\title{
A contribuição de Milton Santos para os estudos de ecossistemas das mídias
}

\section{Fabio B. Josgrilberg ${ }^{1}$}

Recibido: 2015-08-08

Enviado a pares: 2015-08-08

DOI: $10.5294 /$ pacla.2015.18.4.10
Aprobado por pares: 2015-09-10

Aceptado: 2015-09-21

Para citar este artículo / To reference this article / Para citar este artigo Josgrillberg, F. B. (Diciembre de 2015). A contribuição de Milton Santos para os estudos de ecossistemas das mídias. Palabra Clave, 18(4), 1196-1214. DOI: 10.5294/pacla.2015.18.4.10

\section{Resumo}

Este artigo tem por objetivo apresentar possíveis contribuições do geógrafo brasileiro Milton Santos para a análise dos ecossistemas das mídias. O texto busca dialogar com a tradição dos estudos comunicacionais conhecidos como ecologia das mídias, que é altamente influenciada por nomes como Marshall McLuhan, Neil Postman e Walter Ong. $\mathrm{O}$ artigo também se apoia em conceitos e metáforas extraídas das ciências dos ecossistemas, e conclui que a principal contribuição de Santos para o debate está em como ele articula a questão do poder econômico e técnico à sua análise do espaço geográfico fazendo uso de abordagens sistêmicas e dialéticas.

\section{Palavras-chave}

Comunicação, ecossistemas, mídia, Milton Santos, poder (Fonte: Tesauro da Unesco).

1 Universidade Metodista de São Paulo, Brasil. fabio.josgrilberg@metodista.br. 


\section{El aporte de Milton Santos a los estudios de ecosistemas de los medios}

\section{Resumen}

El artículo tiene como objetivo presentar posibles aportes del geógrafo brasileño Milton Santos al análisis de los ecosistemas de los medios. El texto busca dialogar con la tradición de los estudios comunicacionales conocidos como ecología de los medios, que es altamente influenciada por nombres como Marshall McLuhan, Neil Postman y Walter Ong. El artículo también se apoya en conceptos y metáforas retiradas de las ciencias de los ecosistemas, y concluye que el principal aporte de Santos al debate está en cómo él articula la cuestión del poder económico y técnico a su análisis del espacio geográfico haciendo uso de abordajes sistémicos y dialécticos.

\section{Palabras clave}

Comunicación, ecosistemas, medios, Milton Santos (Fuente: Tesauro de la Unesco). 


\section{The Contribution of Milton Santos Ecosystem Studies Media}

\section{Abstract}

The article aims to present possible contributions of the Brazilian geographer Milton Santos ecosystem analysis of the media. The text seeks to dialogue with the tradition known as communication studies and media ecology, which is highly influenced by names like Marshall McLuhan, Neil Postman and Walter Ong. The article is also supported by concepts and metaphors withdrawn ecosystem science, and concludes that the main contribution to the debate is Santos as he articulates the question of economic power and technical analysis of the geographical area using systemic approaches and dialectical.

\section{Keywords}

Communication, ecosystems, media, Milton Santos (Source: Unesco Thesaurus). 


\section{Introdução}

Os estudos sobre ecossistemas representam atualmente grande parte das pesquisas em ecologia. Enquanto o termo ecologia foi cunhado pelo biólogo Ernst Haeckel em 1866, o conceito de ecossistema foi usado formalmente pela primeira vez pelo botânico inglês Arthur Tansley em 1935, ainda que ideias semelhantes circulassem há quase um século antes (Weathers, Strayer, David e Likens, 2013). Em larga medida, o interesse sobre abordagens ecológicas de caráter holístico se espalhou pelas ciências sociais e humanas no pós-guerra. A obra seminal nesse período foi Fundamentals of Ecology (Odum e Odum, 1953), de Eugene P. Odum com seu irmão Howard T. Odum. O movimento em torno da ecologia levou pesquisadores e pesquisadoras a explorarem novas dimensões da interação do ser humano com o ambiente.

Nos estudos sobre comunicação, a tradição da ecologia das mídias se inspira em diferentes tradições e campos científicos, mas é possível identificar três nomes centrais: Marshall McLuhan, Walter Ong e Neil Postman. Outros autores como Harold Innis, James Carey, Lewis Munford e Jacques Ellul, para citar alguns, também podem ser incluídos nas origens dessa linha de pensamento (Scolari, 2012; Strate, 2004). Neil Postman, por sua vez, quando da conferência de abertura do primeiro encontro da Media Ecology Association (http://www.media-ecology.org/), humoradamente reconhece Jacques Ellul, Marshal McLuhan, Eric Havelock e Susanne Langer como Abraão, Moisés, David e Ester da ecologia das mídias (Postman, 2000).

A tradição das pesquisas sobre a ecologia das mídias está baseada no que Ong veio a definir como "open-system awareness", uma espécie de compreensão sobre a abertura do indivíduo ao ambiente em que está inserido que leva a exploração intelectual a múltiplas direções (Ong, 1977; Strate, 2004). Para Ong, "a preocupação ecológica é um novo estado de consciência, o que há de definitivo em termos de ciência (awareness) sobre sistemas abertos. Seu desejo (thrust) é oposto dialético do desejo de isolar a escrita e a impressão" e, mais adiante, "somente um paradigma de sistema aberto representa o indivíduo na maneira com ele tem de viver, ou seja, em con- 
texto, em relação intrínseca com o outro, o exterior, o 'ambiente” (Ong, 1977, p. 278).

Apesar da genealogia complexa dos estudos sobre a "ecologia das mídias", reconhece-se em Neil Postman o estudioso que primeiro introduziu o conceito formalmente, em uma conferência proferida no encontro anual do National Council of Teachers of English, ano de 1968. No evento, o intelectual norte-americano define a ecologia das mídias como o "estudo das mídias como ambiente”. Postman reconheceu que, a rigor, não criava algo novo, mas nomeava uma estratégia de estudos que já estava em andamento. McLuhan, de fato, usou a expressão anos antes em uma comunicação pessoal. No início da década de 1970, Postman inaugura o primeiro programa de doutorado em ecologia das mídias na New York University (Postman, 2000; Scolari, 2012; Strate, 2004).

Na sua definição mais conhecida,

A ecologia das mídias olha para a questão de como os meios de comunicação afetam a percepção humana, entendimento, sentimento e valor; e como nossa interação com os meios facilitam ou impedem nossas chances de sobrevivência. [...] A palavra ecologia implica 0 estudo dos ambientes: sua estrutura, conteúdo e impacto nas pessoas. [...] A ecologia das mídias é 0 estudo das mídias como ambientes (Postman, 1970).

\section{Para Postman,}

[...] os seres humanos vivem em dois tipos diferentes de ambiente. Um é o ambiente natural que consiste de coisas como 0 ar, árvores, rios e lagartas. 0 outro é 0 ambiente das mídias, que consiste de linguagem números, imagens, hologramas e todos os outros símbolos, técnicas e maquinaria que nos fazem ser o que somos (Postman, 2000).

Mais do que isso, no encerramento da conferência do primeiro encontro da Media Ecology Association, Postman chega a afirmar que o estudo da ecologia das mídias "existe para fazer avançar nossos insights sobre como nos situamos como seres humanos, como estamos moralmente na jornada que vivemos" (Postman, 2000, p. 16). E, se você não concorda com a mis- 
são moral da ecologia das mídias, ainda nas palavras de Postman, "você está errado” (Postman, 2000). Sim, a ecologia das mídias busca se posicionar moral e politicamente. É nesse viés crítico que reside parte das diferenças com a abordagens mcluhanianas.

O pensamento McLuhan é mais focado na dimensão tecnológica. Na introdução da segunda edição do clássico Understanding Media, o célebre intelectual canadense afirma que "o 'meio é a mensagem' significa, em termos da era eletrônica, que um ambiente totalmente novo foi criado. $\mathrm{O}$ 'conteúdo' desse ambiente novo é o ambiente mecanizado antigo da era industrial reprocessado" (McLuhan, 2003, p. 13). Em entrevista para a TV em 1977, quando perguntado sobre o significado de "ecologia das mídias", McLuhan responde que "significa organizar as várias mídias para se ajudarem de tal modo que não se cancelem umas às outras, para um meio suportar o outro" (McLuhan citado por Strate, 2004 p. 4). Há nessas respostas uma dimensão cara à ciência dos ecossistemas, que é a descrição de como as espécies se adaptam e se reorganizam no ambiente.

Entre ideias vagas e conceitos mais estruturados, as pesquisas sobre os fenômenos comunicacionais navegam entre os limites e as possibilidades de metáforas ecológicas; figuras que inspiram a formulação de novas perguntas e compreensões, mas que também carregam ambições de validação científica.

Scolari, por exemplo, busca aprofundar a compreensão da "emergência", "dominância”, "sobrevivência" e "extinção" das mídias, bem como oferece interpretações sobre a proposta das mídias como "ambiente", como "espécies" e a aplicabilidade de conceitos como "evolução", "interface" e "hibridização", todos oriundos da biologia. O autor investiga a metáfora biológica não sem antes alertar para os seus limites e possibilidades no campo das ciências humanas e sociais (Scolari, 2012; 2013).

Já Canavilhas explora o "novo ecossistema midiático" em termos de fatores "midiáticos", "contextuais" e "tecno-ambientais" ao tratá-los como correspondentes aos fatores biológicos em estudos tradicionais de ecossistemas 
(Canavilhas, 2011). O autor busca inclusive avançar com propostas para o ensino do jornalismo diante das alterações no ecossistema comunicacional (Canavilhas, 2013).

Este texto pretende avaliar a possível contribuição de Milton Santos para esse debate em torno dos novos ecossistemas midiáticos.

\section{0 espaço, a técnica, as redes e 0 ecossistema midiático}

Como referência para os leitores e leitoras menos familiarizados com o geógrafo brasileiro, Milton Santos nasceu em 3 de maio de 1926, em Brotas de Macaúbas, Bahia (nordeste do Brasil). Formou-se bacharel em Direito pela Universidade Federal da Bahia em 1948, doutorou-se em Geografia pela Universidade de Strasbourg em 1958. Em 1949, paralelamente às atividades acadêmicas, foi correspondente do jornal A Tarde, na Bahia, e tornou-se redator de 1954 até 1964, quando, após um período preso, deixa o país em razão do Golpe Militar. A partir daí, entrou no circuito internacional acadêmico e retornou ao Brasil em 1977. Após dois anos, inseriu-se definitivamente no meio científico brasileiro. Destaque-se ainda que, em 1994, recebeu o Prêmio Internacional de Geografia Vautrin Lud, a maior honraria da área. Em 24 de junho de 2001, Santos veio a falecer ${ }^{2}$ (N. Santos, n.d.).

Com vasta publicação em diferentes idiomas, é possível afirmar que a trajetória intelectual de Santos culmina em A Natureza do espaço: Técnica e tempo. Razão e emoção (Santos, 2002), cuja primeira edição, deve-se destacar, surge em 1996. É nessa obra que o geógrafo se esforça para produzir um "sistema de ideias que seja, ao mesmo tempo, um ponto de partida para apresentação de um sistema descritivo e de um sistema interpretativo da geografia" (Santos, 2002, p. 18). Por trás da empreitada, a pergunta sobre o que é a geografia e uma tentativa de reposta que partisse não da disciplina, mas sim de seu objeto: o espaço (Santos, 2002, p. 19).

2 Os dados biográficos de Milton Santos são baseados nas informações disponíveis no site do autor. Esses e outros dados podem ser acessados na página miltonsantos.com.br. 
A angústia de Santos face ao estado dos estudos sobre a geografia, "que sucumbiu às fragilidades do enfoque da pós-modernidade, cuja versão popular é uma abordagem frequentemente adjetival e metafórica” (Santos, 2002, p. 19), não deixa de encontrar semelhança no esforço de alguns pesquisadores e pesquisadoras em construir o "campo da comunicação". O resultado, no caso de Santos e da geografia, é uma obra de grande rigor teórico e, o que é raro, extremamente elegante e sensível.

Se Santos alcançou seus objetivos na geografia, cabe aos geógrafos avaliarem. Para os estudiosos da comunicação, o que se tem à disposição é um sistema de ideias inspirador e complexo, que muitas vezes antecipou explicações importadas da Europa e dos Estados Unidos de maneira teoricamente mais consistente e que, com alguma frequência, oferece alternativas interessantes à reflexão sobre os processos comunicacionais e ecossistemas de mídias do atual período técnico.

O maior potencial de contribuição para as pesquisas sobre os ecossistemas de mídia talvez esteja na maneira como Santos apresenta o conceito de espaço. A metáfora espacial, é claro, não chega a ser uma novidade. Com a expansão da internet como um dos principais meios de comunicação do atual período técnico, verificou-se a atração provocada por metáforas espaciais para melhor compreensão dos processos comunicacionais. É possível afirmar que a principal delas seria o ciberespaço, que se consagrou na década de 1980 por meio do romance Neuromancer, de William Gibson (1984). De lá para cá, as variações se proliferaram à medida que se obtinha uma melhor compreensão dos problemas teóricos que envolvia a internet. As diferentes relações e práticas sociais no espaço urbano, onde há maior concentração de redes de telecomunicações, e a mediação das distâncias contribuíram para uma estimulante imbricação de vocabulários que articula geografia, ecossistemas, arquitetura, telecomunicações, ciências da computação e cultura cotidiana.

A tradição das metáforas espaciais não surgiu com as mídias digitais, mas se construiu a partir de uma longa tradição dentro das ciências sociais. É comum a eleição de uma "metáfora mestre" para organizar o argumento 
em torno de um determinado objeto de estudo (Silber, 1995), tais como organismo (biologia) ou capital (econômica). As metáforas espaciais, em especial, são recorrentes no campo das ciências sociais, seja por sua familiaridade com a linguagem cotidiana, seja por ser a espacialidade uma dimensão fundamental da vivência fenomenológica dos indivíduos.

A utilização do espaço como metáfora é estimulante para, por exemplo, refletir sobre a cultura e suas relações sociais, vide os pensamentos de Henry Lefebvre (produção do espaço) ou Michel de Certeau (lugar/espaço) (Certeau, 1990; Lefevbre, 1991). McLuhan, mestre na utilização de metáforas para expor suas ideias — não por acaso, dada a sua formação em literatura-, também recorreu a diferentes metáforas espaciais. Para Gow, "espaço visual e acústico servem como metáforas estruturais, orientadoras e ontológicas baseadas no princípio de experimentação, sistematicidade e assimetria" (Gow, 2001). No Brasil, Lemos defendeu a existência de "territórios informacionais” nos quais as redes de telecomunicações se articulavam com o território físico (Lemos, 2007).

No caso de Santos, há que se distinguir o espaço como metáfora, como a ideia de um ciberespaço, e o espaço como dimensão da vida humana ou conceito-chave para a geografia. Muitas vezes, as metáforas e a experiência espacial se influenciam mutuamente em um processo permeável e de difícil precisão (Silber, 1995). Contudo, na elaboração teórica de Santos, o espaço é o seu objeto de estudo fundado em uma construção ontológica.

A evolução teórica do conceito de espaço nas teorias de Santos evoluiu de um "um conjunto de fixos e fluxos", ao final da década de 1970, para a tentativa de se pensar a "configuração territorial" e as "relações sociais", na década de 1980, até se consolidar como "conjunto indissociável de sistemas de objetos e sistemas de ação” (Santos, 2002, p. 62). Em sua definição última, a proposta de Santos valoriza a ação humana recorrendo a um outro conceito central em sua ontologia do espaço: a técnica. Em sua definição mais objetiva, "as técnicas são um conjunto de meios instrumentais e sociais, com os quais o homem realiza sua vida, produz e, ao mesmo tempo, cria espaço" (Santos, 2002, p. 29). 
Ao apresentar um sistema de objetos e um sistema de ações, elementos abióticos e bióticos na ciência dos ecossistemas, Santos não estabelece uma dicotomia, mas uma relação dialética e indissociável entre os interagentes do espaço; uma relação que se organiza de maneira sistêmica em que sistemas de objetos prévios, constituídos por objetos naturais ou artificiais, orientam sistemas de ação e são transformados por estes. Sistemas que podem ser "contraditórios" ou "solidários" (Santos, 2002, p. 63). Dessa forma, na sua análise, abordagens sistêmicas e dialéticas se complementam.

No atual período técnico, a que Santos chama de científico-informacional (Santos, 2002, p. 239), há cada vez mais objetos técnicos artificiais que constituem uma "paisagem" - algo como a compreensão que se tem na ecologia das mídias como ambiente. No entanto, o objeto técnico apenas ganha significado na ação humana. A interpretação desses objetos técnicos somente é possível a partir de uma compreensão da relação entre a ação e a racionalidade técnica do objeto.

Entre o objeto e a ação, há uma relação dialética entre a intencionalidade de um e outro, intencionalidade no sentido fenomenológico husserliano (Santos, 2002). Há, de um lado, o fato de o objeto sugerir um determinado uso que entra em relação dialética com intencionalidade do ser humano. Este, por sua vez, visa ao mundo e lhe dá sentido a partir de vivências que não são apenas aquelas sugeridas pelas características físicas e pela racionalidade do objeto técnico.

Na geografia de Santos, o corpo e toda sua potência perceptiva e de ação é um elemento fundamental. Em suas palavras, é "pela corporeidade que o homem participa do processo de ação” (Santos, 2002, p. 80). Nesse ponto, apresenta-se uma chave para o diálogo com a discussão sobre como as mídias alteram a percepção humana, tal como explorada pelos estudos da ecologia das mídias. Dos principais nomes dessa tradição, Ong seria um dos que mais claramente são influenciados pela tradição filosófica da fenomenologia.

Santos não elabora teoricamente a sua compreensão de intencionalidade, mas sua análise evidencia uma relação dialética entre mundo, constituído de objetos naturais e técnicos, e o ser. Os objetos técnicos são carregados 
de uma racionalidade que lhes é própria, fruto da organização racional da técnica (Santos, 2002); ou seja, a racionalidade dos objetos advém de um conjunto de meios instrumentais e de suas características físicas e sociais, tais como discursos, processos de estandardização ou o sistema econômico. Tal organização de sistemas visa sempre ao controle para a garantia de sua maior eficácia. Desse modo, as técnicas e seus objetos técnicos se impõem ao território, de certa forma, com "indiferença ao meio em que se instalam” (Santos, 2002, p. 180); são produtos da história e produtoras de história, sendo que toda nova técnica leva a uma nova percepção do mundo e do tempo. No atual período técnico, a força motriz do processo de autoexpansão é a mais-valia capitalista (Santos, 2002).

É importante ressaltar que nenhuma técnica se impõe como absoluto, mas se articula sistemicamente com outras técnicas (Santos, 2002). Em um determinado período histórico, uma técnica pode até parecer universal como, por exemplo, a computação, mas ela não é absoluta porque está articulada com outras técnicas, tais como o sistema econômico, oralidade, produção agrícola, dentre outras. A adaptabilidade das técnicas, em alguma medida, dialoga com a maneira como os estudos da ecologia das mídias investigam a evolução dos meios de comunicação.

Com base nos conceitos elaborados Santos sobre o espaço e sua relação com as técnicas, não seria demais afirmar que o ciberespaço é tão presente quanto um acidente geográfico e ambos são constituintes do mesmo espaço. Nada mais próximo do que a compreensão que se tem dos meios de comunicação na análise inspirada pela metáfora do ecossistema, em que elementos bióticos a abióticos interagem.

O ciberespaço é um elemento do espaço e não "outro espaço". O conceito de espaço não é uma metáfora ou um sistema independente (ciber), mas algo concreto articulado por sistemas de objetos e sistemas de ações, mobilizados por técnicas do atual período. Nesse sentido e a título de exemplo, é possível montar um quadro ilustrativo de alguns sistemas de ações e objetos constituintes do espaço urbano metropolitano, conforme o Quadro 1. 


\section{Quadro 1 \\ Sistema de objetos e sistema de ações}

\begin{tabular}{|c|c|}
\hline Sistema de objetos & Sistema de ações \\
\hline Rede de telecomunicações & Processos comunicacionais \\
\hline Arquitetura urbana & Mobilidade \\
\hline Natureza urbana & Práticas cotidianas \\
\hline Terminais digitais & Ação baseada na razão técnica \\
\hline
\end{tabular}

Fonte: elaboração do autor.

A internet, enquanto um sistema de redes que obedece a determinados protocolos de comunicação e transporte de dados, é um objeto técnico entre outros. Sua organização está sistemicamente articulada com outros sistemas de objetos e ações. Sua função pode mudar na articulação sistêmica; sua forma "nos dá o ponto de partida, mas não o de chegada" aqui, a inspiração de Santos vem de Georg Simmel.

O espaço geográfico é um híbrido e, nesse sentido, a proposta de Milton Santos se aproxima das teorizações de outros autores. Lemos, por exemplo, apresenta semelhante sugestão de hibridização ao afirmar que o "território informacional não é o ciberespaço, mas o espaço movente, híbrido, formado pela relação entre o espaço eletrônico e físico"; trata-se de um "lugar, dependente dos espaços físico e eletrônico", configurado por "atividades sociais" (Lemos, 2007b, p. 128).

O que talvez seja peculiar aos sistemas de técnicas que organizam a internet é a velocidade com que eles garantem o controle, expansão e resiliência das redes. Santos chamou essas novas técnicas de "técnicas doces" (Santos, 2004), pois são de fácil reprodução e aprendizado. No entanto, como toda técnica, visam também ao controle, à convergência e a processos de estandardização. Isso é particularmente evidente nos sistemas de telecomunicações. O diagnóstico de Santos é preciso: "Ele [o computador] não simplifica o que é complexo, mas contribui à sua apresentação simplificada, o que somente obtém à custa de um processo brutal de redução" (Santos, 2002, p. 186). Sem esse processo de controle e redução, a computação perderia a sua eficácia. 
No caso das redes da internet, a tendência à centralização para maior controle e maiores ganhos não é, em hipótese alguma, uma surpresa. Antes, trata-se de uma característica comum às redes técnicas. Baran, nos primórdios das reflexões sobre as redes distribuídas, previu isso claramente: "Serviços de comunicação e transporte historicamente tendem a formar 'monopólios naturais'. A razão é compreensível. É muito mais barato compartilhar o uso de uma grande entidade existente do que construir a própria estrutura” (Baran, 1967, p. 76).

A leitura mais refinada de Santos vai além do viés econômico já destacado por Baran e não se restringe apenas aos fenômenos das redes técnicas. As redes, no caso do geógrafo brasileiro, podem ser pensadas como elementos dos sistemas técnicos vigentes. Aqui, talvez valha a citação um pouco mais longa:

A técnica se alimenta da estandardização, apoia a produção de protótipos e normas, atribuindo ao método apenas a sua dimensão lógica, cada intervenção técnica sendo uma redução (de fatos, de instrumentos, de forças e de meios), servida por um discurso. [...] Os sistemas técnicos são, cada vez mais, exigentes de um controle coordenado. De uma multiplicidade de instalações uma pluralidade de comandos encaminhamo-nos para um comando único, ou, ao menos, unificado (Santos, 2002, p. 182).

Quanto à internet, tais características uniformizadoras dos sistemas técnicos e das redes enquanto elementos dos atuais sistemas técnicos, ficam evidentes na articulação das infraestruturas e de seus serviços. Ainda que não exista um comando único, a unificação do controle é evidente na organização dos servidores-raiz e na concentração de provedores de interconexões locais, regionais e globais. A concentração também passa pela produção de conteúdo, seja pela centralização das ferramentas de busca, mídias sociais mais acessadas, seja por portais de conteúdos. Há ainda a unificação de comandos por meios dos sistemas operacionais em terminais fixos ou móveis.

Porém, "nem tudo é rede" e, assim com o espaço, as redes são "instáveis" e "heterogêneas" em razão da ação humana (Santos, 2002, pp. 267 268). Ao tratar de redes, Santos elabora uma série de elementos teóricos 
que podem ser bastante úteis aos estudos de comunicação. O geógrafo parte do princípio de que o termo rede, em voga, proliferou-se nas ciências humanas e sociais de maneira não necessariamente crítica.

Santos assume as duas matrizes principais nas definições de rede: a que leva em consideração tanto os seus aspectos materiais, como a conceituada pela engenharia, quanto as suas dimensões social e política (Santos, 2002). Do ponto de vista analítico, destaca as dimensões "genética" e "atual": a primeira, relativa à constituição diacrônica dos elementos técnicos constituintes da rede; a segunda, também que leva em conta a dimensão técnica, mas com atenção à relação entre os elementos e à vida cotidiana social (Santos, 2002, p. 263).

As duas dimensões analíticas, atual e genética, não podem ser pensadas separadamente. Contudo, determinam uma diferenciação que será fundamental para constituição de um conjunto de polos dialéticos de análise. Uma primeira relação é entre os "fixos" e os "fluxos" (Santos, 2002, p. 277). Os fixos, os pontos que conectam a rede, revelam a "base técnica" da rede. Compreender uma rede por seus fixos é deixar de levar em conta que existe uma geografia da rede: fluxos "lentos" e "rápidos", as realidades locais e globais. A rede global tem por ambição a fluidez, que é uma "categoria sociotécnica”, dependente tanto de seus objetos técnicos quanto de uma série de outras ações que garantem o fluxo da rede. Não basta produzir, há de se fazer circular a informação.

Ao trazer a reflexão de Santos para o atual estado do debate sobre a internet, vê-se quão paradoxal pode se tornar a discussão em torno da fluidez. O objetivo parece consensual: garantir a universalização do acesso para a promoção dos fluxos informacionais e dos mais diversos processos sociais, o que levaria ao desenvolvimento da sociedade como um todo. Sendo a internet um conjunto de redes distribuídas, pressupõe-se uma equivalência entre os pontos (fixos) de tal modo que a expansão de sua infraestrutura e a produção de fluxos sejam livres de quaisquer obstáculos, desde que obedeçam a protocolos de comunicação e identificação que garantam o seu funcionamento. Diversos espectros políticos não teriam problemas em concordar com os princípios de liberdade pressupostos 
em uma rede distribuída, sejam ativistas da esquerda democrática sejam capitalistas do neoliberalismo mais predatório.

O acordo sobre a fluidez e a liberdade na internet, contudo, está longe de ser consensual. Em nome de uma noção limitada, por vezes pusilânime, de liberdade e justiça, há esforços em direções opostas. A ambição de liberdade e fluidez no setor de telecomunicações e de produção de conteúdos, por exemplo, pode levar à formação de grandes grupos que acabam por concentrar as principais operações, tal como previsto por Baran na década de 1960 (Baran, 1967).

A questão é tão paradoxal que o discurso da liberdade da rede deixa de ser interessante para os defensores da desregulamentação de mercado quando há possibilidade de ganho com práticas restritivas ou ofensivas à liberdade, vide o debate em torno da neutralidade da rede e privacidade durante a tramitação do Marco Civil da Internet no Brasil (CGI.br, 2013). Nesse sentido, o diagnóstico de Santos, uma vez mais, foi preciso: "A existência das redes é inseparável da questão do poder” (Santos, 2002, p. 270). É por essa razão que, em geral, a opção radical pela liberdade na internet se encontra mais solidamente defendida entre grupos que, de fato, buscam o bem comum.

A análise de Santos não chega a desenvolver de maneira tão detalhada a tendência de concentração dos fluxos ou mesmo a relação entre os fixos. Discute, porém, a existência de forças centrípetas e centrífugas nos sistemas de técnicas presentes nos territórios. As forças centrípetas são forças de agregação, "resultam do processo econômico e do processo social, e tanto podem estar subordinados às regularidades do processo de produção quanto às surpresas da intersubjetividade" (Santos, 2002, p. 286). Nesse caso, há um vetor de força em direção da homogeneização entre o campo e a cidade, assim como ocorre com a agricultura moderna, cuja base tecnológica normalmente é adquirida nos centros urbanos mais próximos.

Já as forças centrífugas promovem a "desagregação" ao retirar da "região os elementos do seu próprio comando" (Santos, 2002, p. 287). São exemplos de forças centrífugas o comércio internacional, as grandes 
indústrias, as demandas da metrópole ou do capital financeiro. Enquanto as forças centrípetas se apresentam em movimentos horizontais, as forças centrífugas agem sobre o território verticalmente. As forças centrípetas são exercidas por meio da comunicação e processos lentos; as forças centrífugas por meio da informação veloz, que invade o território por força de redes globais externas (Santos, 2002).

Apesar da verticalidade e poder das forças centrífugas globais desagregadoras, que transferem o centro de comando para fora da região, a informação se instala em relação dialética ao que Santos chamou de "rugosidades", ou seja, as heranças físico-territoriais, socioterritoriais e sociogeográficas. Assim, a informação exógena não se impõe de maneira previsível. Ao final, "o valor de um dado elemento no espaço, seja ele o objeto técnico mais concreto ou mais performante, é dado pelo conjunto da sociedade, e se exprime através da realidade do espaço em que se encaixou (Santos, 2002, p. 43).

\section{Conclusão}

É possível tratar os estudos de ecossistemas como um campo específico da ciência. Em sua definição mais simples e objetiva, um "ecossistema é um sistema interativo constituído de objetos vivos e sem vida em um volume de espaço específico" (Weathers et al., 2013) ${ }^{3}$.

A definição de Weathers et al. permite estudar um ecossistema em termos do seu balanço de massa acompanhando o movimento e o destino de seus objetos, dentro de limites estabelecidos pelo pesquisador ou pesquisadora no que se refere a espaço e tempo a título de mensurar os fluxos existentes. Embora limitados para análise, assume-se que o ecossistema estudado está aberto ao fluxo de energia e materiais de sistemas próximos. A proposta também valoriza a importância dos elementos vivos ou não no controle de funções e respostas dentro do sistema (Weathers et al., 2013).

A ciência dos ecossistemas, de maneira resumida, esforça-se por descrever estruturas e funções por meio de análises de história natural,

3 Todas as traduções foram feitas pelo autor. 
teóricas e de modelos conceituais, estudos de longo prazo e experimentos. Na descrição de suas funções, os ecossistemas podem ser caracterizados como fonte ou repositório de certos materiais, ou seja, avaliam-se os inputs e outputs do sistema. Nos estudos comparativos, os cientistas buscam descrever a estrutura, funções, controle e dinâmica temporal para classificá-los. Com frequência, os ecossistemas são descritos pela quantidade e tipos de seus objetos, com foco nos principais materiais e organismos (Weathers et al., 2013).

As chaves para a aproximação entre a geografia de Santos e os estudos sobre ecossistemas podem ser encontradas em, pelo menos, duas dimensões: 1) na descrição e na compreensão das relações estabelecidas entre elementos bióticos e abióticos (ecossistemas); 2) na necessidade de análise dos fluxos internos em relação a sistemas vizinhos. Funções, estruturas, controles, inputs e outputs (fluxos) formam um conjunto de metáforas que poderiam facilmente dialogar com as ideias de Milton Santos. Em um possível modelo de ecossistema das mídias, a maior contribuição do geógrafo brasileiro reside na maneira como ele desenvolve a relação sistêmica entre os objetos e ações humanas sustentadas por diferentes técnicas em permanente relação dialética. Essa abordagem traz para o centro da análise sistêmica a questão do poder.

A preocupação social de Milton Santos está relacionada com as questões apresentadas por teóricos da tradição da ecologia das mídias, que, como já observado no início deste texto, "existe para fazer avançar nossos insights sobre como nos situamos como seres humanos, como estamos moralmente na jornada que vivemos" (Postman, 2000). Santos, de acordo com sua ambição do livro A natureza do espaço, e com sua única citação de Neil Postman nesse texto, apresenta mais "uma forma de contar histórias" (Santos, 2002, p. 22); histórias sobre as mídias e as atuais técnicas do período técnico-científico-informacional e sobre como seria possível dar um novo sentido existencial a elas (Santos, 2004). 


\section{Referências}

Baran, P. (1967). The future computer utility. National Affairs, 8. Acesso: 14 set. 2015. Disponível em: http://www.nationalaffairs.com/public_interest/detail/the-future-computer-utility

Canavilhas, J. (2011). El nuevo ecosistema mediático. Index.comunicación, 1 (1), 13-24.

Canavilhas, J. (2013). El periodismo en los tiempos de un nuevo ecosistema mediático: propuestas para la enseñanza superior. Historia y Comunicación Social, 18 nov., 511-521.

Certeau, M. de. (1990). L'invention du quotidien. 1. Arts de faire. Paris: Gallimard.

CGI.br. (2013). CGI e o Marco Civil da Internet. CGI.br. Acesso: 14 set. 2015. Disponível em http://www.cgi.br/publicacoes/documentacao/CGI-e-o-Marco-Civil.pdf

Gibson, W. (1984). Neuromancer. Nova York: Ace Books.

Gow, G. (2001). Spatial metaphor in the work of Marshall McLuhan. Canadian Journal of Communication, 26 (abril). Acesso: 14 set. 2015. Disponível em: http://www.cjc-online.ca/index.php/journal/article/view/1254/1251

Lefevbre, H. (1991). The production of space. Oxford: Basil Blackwell.

Lemos, A. (2007a). Cidade e mobilidade. Telefones celulares, funções pósmassivas e territórios informacionais. Matrizes, 1(1), 121-137. Acesso: 14 set. 2015. Disponível em http://www.usp.br/matrizes/img/01/Media1AndreLemos.pdf

Mc Luhan, M. (2003). Understanding media: The extensions of man. BerkeleyCA: Gingko Press. 
Odum, E. P. e Odum, H. T. (1953). Fundamentals of ecology. Philadelphia: Saunders.

Ong, W. J. (1977). Interfaces of the word: Studies in the evolution of consciousness and culture (1st ed.). Ithaca-NY: Cornell University Press. doi: $10.7591 /$ j.cttq42vq

Postman, N. (1970). The reformed english curriculum. Em A. C. Eurich (ed.), High school 1980: The shape of the future in american secondary education. Nova York: Pitman.

Postman, N. (2000). The humanism of media ecology. Em Proceedings of the Media Ecology Association, vol 1, 10-16.

Santos, M. (2002). A natureza do espaço: técnica e tempo. Razão e emoção. São Paulo: EDUSP.

Santos, M. (2004). Por uma outra globalização: do pensamento único à consciência universal. Rio de Janeiro: Record.

Scolari, C. A. (2012). Media ecology: Exploring the metahpor to expand the theory. Communication Theory, 22, 204-225.

Scolari, C.A. (2013). Emergence, dominance, survival and extinction in the media ecology. International Journal of Communication, 7 (julho), 24.

Silber, I. (1995). Space, fields, boundaries: The Rise of spatial metaphors in contemporary sociological theory. Social Research, 62(2), 323-355.

Strate, L. (2004). A media ecology review. Communication Research Trends, $23(2), 348$.

Weathers, K., Strayer, D. L. e Likens, G. E. (2013). Fundamentals of ecosystem science. Nova York: Elsevier. 